\title{
SALT ADDITION AND THE RISK OF TYPE 2 DIABETES MELLITUS: a case-control study
}

\author{
Lina Radzeviciene', Rytas Ostrauskas', Evelina Praneviciene ${ }^{2}$
}

${ }^{1}$ Institute of Endocrinology, Medical Academy, Lithuanian University of Health Sciences;

${ }^{2}$ Faculty of Medicine, Medical Academy, Lithuanian University of Health Sciences.

\section{Objectives}

Type 2 diabetes appears to involve interaction between susceptible genetic backgrounds and environmental factors [1]. It's important to identify modifiable risk factors that may help reduce the risk of type 2 diabetes. The WHO suggests a worldwide target of a maximum salt intake for adults of $5 \mathrm{~g}$ per day [2], but the average salt intake in most countries around the world is approximately 9 to $12 \mathrm{~g} / \mathrm{d}$ [3]. Consensus Action on Salt and Health established in the United Kingdom in 1996, actively campaigns to raise awareness of the alleged harmful health effects of salt [4]. Data on salt intake and the risk of type 2 diabetes mellitus are limited. The aim of the study was to assess the relationship between adding salt to prepared meal and the risk of type 2 diabetes mellitus.

\section{Methods}

A case-control study included 234 cases with a newly confirmed diagnosis of type 2 diabetes mellitus during the one whole year and 468 controls which were free of the disease. Cases and controls (ratio 1:2) were matched by gender and age ( \pm 5 years). A specifically designed questionnaire was used to collect information on possible risk factors of type 2 diabetes. Anthropometrical measurements were made according to World Health Organization recommendations. The odds ratios (OR), and 95\% confidence intervals $(\mathrm{Cl})$ for type 2 diabetes were calculated by a conditional logistic regression. All the calculations were performed with the standard STATA 7 software program.

\section{Results}

Fig. 1. Unadjusted odds ratios and $95 \%$ confidence interval for type 2 diabetes mellitus in relation to adding salt to prepared meal

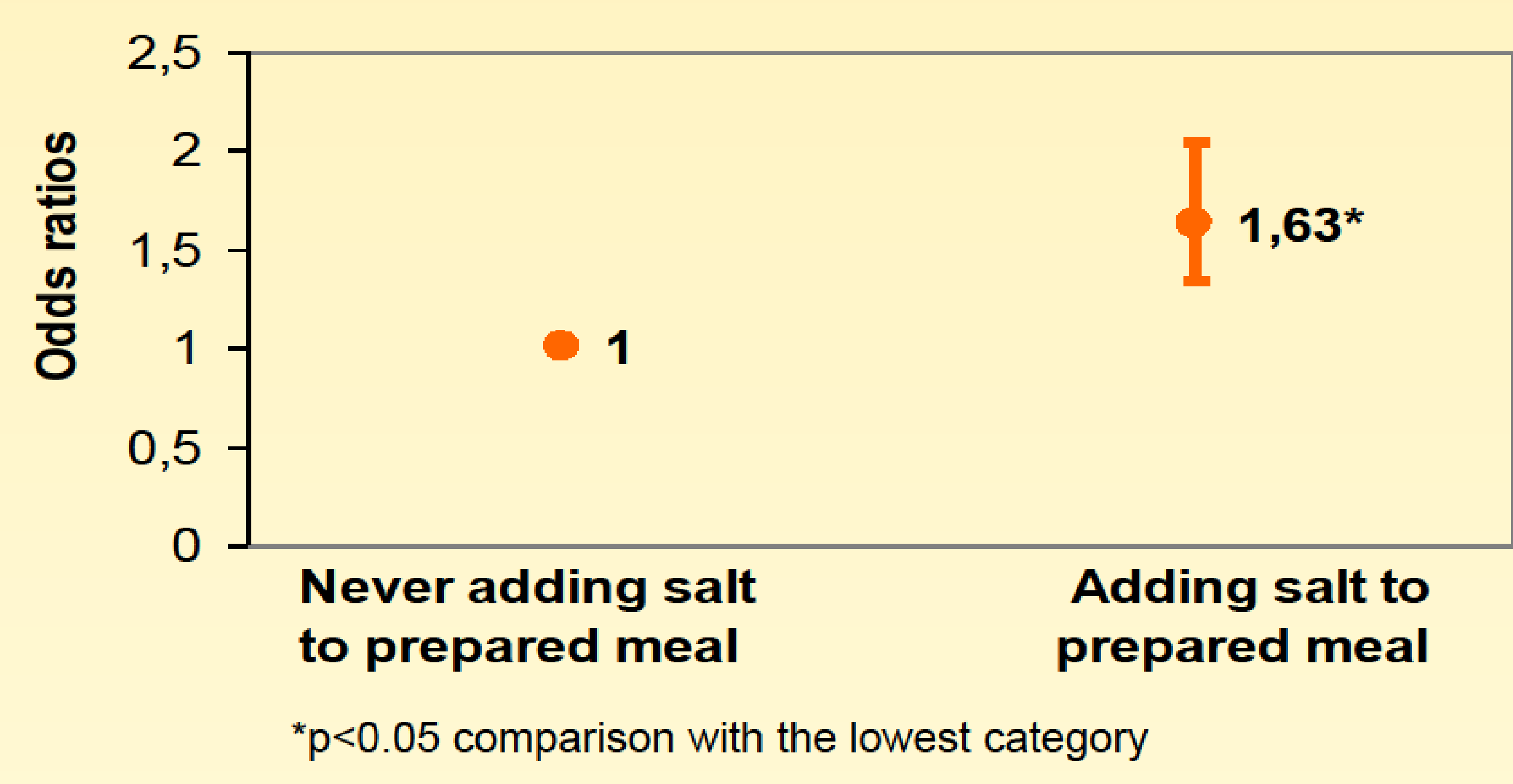

Table 1 . The odds ratios and $95 \%$ confidence interval for type 2 diabetes mellitus in relation to adding salt to prepared meal

\begin{tabular}{|c|c|c|c|c|c|c|}
\hline \multirow{2}{*}{ Variable } & \multirow{2}{*}{ Category } & \multicolumn{2}{|c|}{ Cases } & \multicolumn{2}{|c|}{ Controls } & \multirow{2}{*}{$\begin{array}{c}\text { OR }(95 \% \mathrm{Cl}) \\
\mathrm{p}\end{array}$} \\
\hline & & $\mathrm{n}$ & $\%$ & $\mathrm{n}$ & $\%$ & \\
\hline \multirow[b]{2}{*}{$\begin{array}{l}\text { Adding salt to } \\
\text { prepared meal }\end{array}$} & Never & 117 & 50.00 & 290 & 61.97 & 1.00 \\
\hline & $\begin{array}{l}\text { When it is not enough } \\
\text { or almost every time } \\
\text { without tasting }\end{array}$ & 117 & 50.00 & 178 & 38.03 & $\begin{array}{c}1.82(1.19-2.78) \\
p=0.006\end{array}$ \\
\hline
\end{tabular}

OR adjusted for waist circumference, body mass index, arterial hypertension, plasma triglycerides, eating speed, smoking, family history of diabetes, educational level, occupational status, morning exercise and marital status.

In our study there were $28.21 \%$ men and $71.79 \%$ women. The mean age was 64.09 years (SD=7. 85 ) (range: $39-86$ years) for men and 65.23 years $(S D=8.3)$ (range: $34-86$ years) for women. The cases had higher body mass index and significantly lower education level, compared to the controls. There were more controls without a family history of a first degree relative with diabetes than cases. Variables such as family history of diabetes, education, body mass index, waist circumference, morning exercise, eating speed, cigarette smoking, arterial hypertension, plasma triglycerides, occupational and marital statuses were retained in the models as confounders because their inclusion changed the value of the OR by more than $5 \%$ in any exposure category. After adjusting for possible confounders about two-fold increased risk of type 2 diabetes mellitus was determined in those subjects whose adding salt to prepared meal when it is not enough or almost every time without tasting $(1.82 ; 95 \% \mathrm{Cl} 1.19-2.78 ; \mathrm{p}=0.006)$ vs. subjects whose never adding salt to prepared meal.

\section{Conclusions}

Our data support a possible relationship between adding salt to prepared meal and the increased risk of type 2 diabetes mellitus.

\section{References:}

1. Naser KA, Gruber A, Thomson GA. The emerging pandemic of obesity and diabetes: are we doing enough to prevent a disaster? Int J Clin Pract 2006;60(9):1093-7.

2. World Health Organization. Diet, Nutrition and the prevention of chronic diseases. Report of the Joint WHO/FAO Expert Consultation. Geneva: World Health Organization, 2003 (WHO Technical Report Series, No 916).

3. Brown IJ, Tzoulaki I, Candeias V, et al. Salt intakes around the world: implications for public health. Int J Epidemiol 2009;38:791-813.

4. CASH: Consensus Action on Salt and Health. http://www.actiononsalt.org.uk/(Accessed November 16, 2014). 